\title{
Especificando cimentos para concretos duráveis
}

\author{
SilVia VIeIRA - Gerente Geral de Pesquisa \& Desenvolvimento \\ Votorantim Cimentos
}

\section{INTRODUÇÃO}

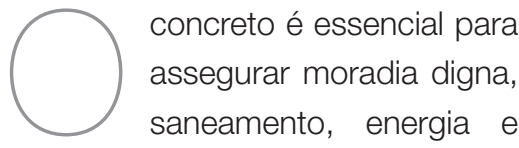
toda a infraestrutura fundamental para a sociedade.

Por outro lado, um dos principais constituintes do concreto é o cimento, cuja produção está associada a quantidades significativas de emissões de $\mathrm{CO}_{2}$. A indústria cimenteira assumiu compromissos audaciosos de redução de sua pegada ambiental e tem adotado medidas para diminuir as emissões relacionadas à produção do cimento. Entre elas, destacam-se o uso de adições de escórias, pozolanas e filer calcário nos cimentos, o emprego de combustíveis alternativos para a calcinação das matérias-primas que levam à formação do clínquer, e pesquisas visando, por exemplo, a captura e uso do $\mathrm{CO}_{2}$. No entanto, para uma contribuição mais efetiva do setor da construção na mitigação do aquecimento global, é preciso produzir, também, concretos com menor impacto ambiental.

O impacto ambiental do concreto pode ser minimizado reduzindo-se o teor de clínquer na mistura, o que é conseguido com o uso de cimentos com maiores teores de adição, diminuindo-se o conteúdo de cimento no concreto a partir da otimização das características dos constituintes e do traço, ou aumentando-se a durabilidade da estrutura, estendendo, assim, sua vida útil. $\mathrm{O}$ aumento da vida útil preserva recursos não renováveis, reduz resíduos gerados pela demolição da estrutura e os custos sociais e de reparos.

A vida útil da estrutura é influenciada por diversos fatores, entre os quais estão o projeto, as condições a que estará exposta, a qualidade de sua execução e a durabilidade dos seus componentes.

Este artigo discute a forma de especificar cimentos, com o objetivo de aumentar a durabilidade dos concretos e, consequentemente, prolongar a vida útil e reduzir a pegada ambiental das estruturas de concreto.

\section{ESPECIFICANDO CIMENTOS PARA CONCRETOS DURÁVEIS}

Existem, essencialmente, duas maneiras de especificar cimentos, ou seja, de forma prescritiva ou baseada em desempenho. Em especificações prescritivas são definidas as características químicas e físicas dos cimentos, enquanto especificações baseadas em desempenho estabelecem as propriedades mecânicas, reológicas e de durabilidade que o cimento deve atingir, independentemente de sua composição. Nas especificações prescritivas, são definidos, por exemplo, os teores de $\mathrm{C}_{3} \mathrm{~A}$, álcalis e finura, enquanto naquelas baseadas em performance poderão ser requeridas a resistência a sulfatos, a capacidade de inibir a reação álcali agregado e o calor de hidratação, sem qualquer restrição à composição do produto.

Uma especificação é o resultado de um conjunto de requerimentos do cliente e de parâmetros estabelecidos nas normas técnicas. Em geral, especificações definem a trabalhabilidade no estado fresco e a resistência à compressão e a durabilidade que o concreto deve ter no estado endurecido. Enquanto a resistência à compressão é especificada baseada em desempenho, a trabalhabilidade e durabilidade ainda são, normalmente, especificadas de modo prescritivo. Para conseguir a trabalhabilidade desejada, no que diz respeito exclusivamente às características do cimento, é definida a sua finura e para a durabilidade, seus teores de $\mathrm{C}_{3} \mathrm{~A}, \mathrm{SO}_{3}$ e álcalis, dependendo do tipo de processo de deterioração ao qual o concreto estará submetido. De qualquer modo, o objetivo de qualquer especificação é garantir o desempenho do concreto aplicado.

\section{ESPECIFICAÇÕES PRESCRITIVAS}

Especificações prescritivas podem não contemplar todos os aspectos relevantes e necessários para assegurar a vida útil definida em projeto. Além disso, elas limitam a otimização das características do cimento, a redução da pegada ambiental de seu processo de fabricação, a redução de custos e a inovação.

Especificações prescritivas são particularmente usadas em obras de infraestrutura ou em concretos expostos a meios agressivos, e muitas das normas e códigos técnicos também têm caráter prescritivo. Isso acontece por falta de confiança entre os agentes da cadeia, falta de 
Tabela 1 - Exemplo de

especificação do cimento

geralmente usado em obra

de barragem

conhecimento técnico sobre quais parâmetros de desempenho deveriam ser considerados e endereçados, falta de ensaios confiáveis para avaliação da durabilidade e pela postura conservadora do meio técnico. Por exemplo, para concretos expostos a ambientes onde há possibilidade de corrosão das armaduras induzida por carbonatação ou penetração de cloretos, os anexos da norma europeia de concreto (EN 206) aplicados na França, Itália e Bélgica permitem o uso de qualquer tipo de cimento contemplado na norma europeia de cimento (EN 197), enquanto os anexos da EN 206 aplicados na Áustria, Alemanha e Suíça restringem os tipos de cimentos que podem ser usados. Naturalmente, esta discrepância não tem fundamento técnico, mas resulta de preconceitos e falta de experiência no uso de alguns cimentos em alguns desses países.

No Brasil, especificações de cimentos para obras de infraestrutura são, frequentemente, uma mistura de critérios prescritivos e de desempenho, como mostra a Tabela 1. Embora não esteja explícito na especificação, os limites dos teores de álcalis visam, provavelmente, evitar a reação álcali-agregado, enquanto os limites dos teores de $\mathrm{SO}_{3}$ e $\mathrm{C}_{3} \mathrm{~A}$ têm como objetivo evitar deterioração por ataque sulfático e, no caso do $\mathrm{C}_{3} \mathrm{~A}$, também assegurar baixo calor de hidratação.

\section{EVITANDO A REAÇÃO ÁLCALI-AGREGADO A PARTIR DA LIMITAÇÃO DO TEOR DE ÁLCALIS}

É comum, em especificações prescritivas, o estabelecimento do teor máximo de álcalis no cimento em 0,60\% (como equivalente alcalino), com o objetivo de evitar reações tipo álcali-agregado. No entanto, vários estudos mostram que nem sempre isso garante a inibição dessas reações expansivas.

Como mostra a Figura 1, um cimento tipo CP IV, com teor de álcalis de 1,33\% e teor de cinzas volantes e filer calcário da ordem de 16\% e 10\%, respectivamente, é capaz de inibir reações álcali-silicato para agregados com certo grau de reatividade, pois apresenta na sua constituição um material pozolânico reconhecidamente inibidor. Da mesma forma, um cimento com teor de álcalis de 0,60\% pode não ser eficaz na inibição dessas reações (Figura 2). Estudos feitos com diferentes agregados e cimentos também demonstram que um mesmo cimento pode ser ou não inibidor da reação álcali-agregado, dependendo da reatividade do agregado (Figura 3).

Além disso, como mostraram Heisige tal. (2016), expansões devidas à reação álcali-agregado podem ser desencadeadas por álcalis externos, introduzidos no concreto depois de endurecido. Assim, a melhor maneira de evitar deterioração por reações álcali-agregado, após uma análise de risco de sua ocorrência, é o uso de cimentos com teores adequados de escórias ou pozolanas, cuja eficácia deve ser atestada por meio de ensaios de laboratório.

\section{INIBINDO ATAQUE SULFÁTICO A PARTIR DA LIMITAÇÃO DO TEOR DE C $\mathrm{C}_{3} \mathrm{~A}$}

Embora a norma de cimento NBR 16697, revisada em 2018, considere resistentes a sulfatos os cimentos que apresentarem expansão menor que 0,03\% aos 56 dias de idade, quando ensaiados pelo método estabelecido pela NBR 13583, ainda é muito comum, em particular para obras de infraestrutura, a limitação do teor de $\mathrm{C}_{3} \mathrm{~A}$ do cimento como uma medida para inibir deterioração por ataque sulfático. Porém, estudos comprovam que o fator determinante para a resistência do concreto a ataques por sulfatos externos é sua relação água/cimento. Em um experimento conduzido por Stark (2002), barras de concreto feitos com cimentos resistentes a sulfatos, segundo a norma ASTM C 150 , foram expostas em condições seve-

\begin{tabular}{|c|c|c|}
\hline \multicolumn{2}{|c|}{ Parâmetro } & Especificação \\
\hline \multicolumn{2}{|c|}{ Resíduo insolúvel (\%) } & $\leq 1,00$ \\
\hline \multicolumn{2}{|c|}{ Perda ao fogo (\%) } & $\leq 3,0$ \\
\hline \multicolumn{2}{|c|}{$\operatorname{MgO}(\%)$} & $\leq 6,5$ \\
\hline \multicolumn{2}{|c|}{$\mathrm{SO}_{3}(\%)$} & $\leq 3,0$ \\
\hline \multicolumn{2}{|c|}{$\mathrm{C}_{3} \mathrm{~S}(\%)$} & $\geq 35,0$ \\
\hline \multicolumn{2}{|c|}{$\mathrm{C}_{3} \mathrm{~A}(\%)$} & $\leq 8,0$ \\
\hline \multicolumn{2}{|c|}{ Álcalis $\left(\mathrm{Na}_{2} \mathrm{O}_{\text {equivalente }}\right)(\%)$} & $\leq 0,6$ \\
\hline \multicolumn{2}{|c|}{$\begin{array}{c}\text { Resíduo na peneira } 200 \\
\text { mesh }(0,075 \mathrm{~mm})(\%)\end{array}$} & $\leq 10$ \\
\hline \multicolumn{2}{|c|}{ Finura (Blaine) (m²/kg) } & $350 \pm 20$ \\
\hline \multicolumn{2}{|c|}{$\begin{array}{c}\text { Expansão em autoclave } \\
(\%)\end{array}$} & $\leq 0,8$ \\
\hline \multicolumn{2}{|c|}{$\begin{array}{l}\text { Tempo de início de pega } \\
\text { (minutos) }\end{array}$} & $\geq 60$ \\
\hline \multicolumn{2}{|c|}{$\begin{array}{l}\text { Tempo de final de pega } \\
\text { (minutos) }\end{array}$} & $\leq 100$ \\
\hline \multirow{3}{*}{$\begin{array}{l}\text { Resistência à } \\
\text { compressão } \\
\text { (MPa) }\end{array}$} & 3 dias & $\geq 15$ \\
\hline & 7 dias & $\geq 25$ \\
\hline & 28 dias & $\geq 40$ \\
\hline \multirow{2}{*}{$\begin{array}{c}\text { Calor de } \\
\text { hidratação } \\
\text { (cal/g) }\end{array}$} & 3 dias & $\leq 60$ \\
\hline & 7 dias & $\leq 70$ \\
\hline
\end{tabular}

ras quanto à presença de sulfatos por 16 anos. Ao final do período, foi observada deterioração no concreto com relação água/cimento igual a 0,65, enquanto o concreto feito com relação água/cimento igual a 0,39 permaneceu intacto.

Monteiro \& Kurtis (2003) também confirmam a importância da relação água/ cimento, com estudos que mostram que concretos com relação água/cimento menores que 0,45 foram capazes de resistir à deterioração por sulfatos, independentemente do teor de $\mathrm{C}_{3} \mathrm{~A}$ do cimento.

De fato, a norma brasileira ABNT NBR 12655: 2015 estabelece valores limites máximos de a/c e mínimos de fck para concretos sujeitos a diferentes condições ambientais de agressividade por sulfatos.

\section{REDUZINDO O CALOR DE HIDRATAČ̃̃O A PARTIR DA LIMITAÇÃO DO TEOR DE ÇA}

O calor de hidratação é um problema 


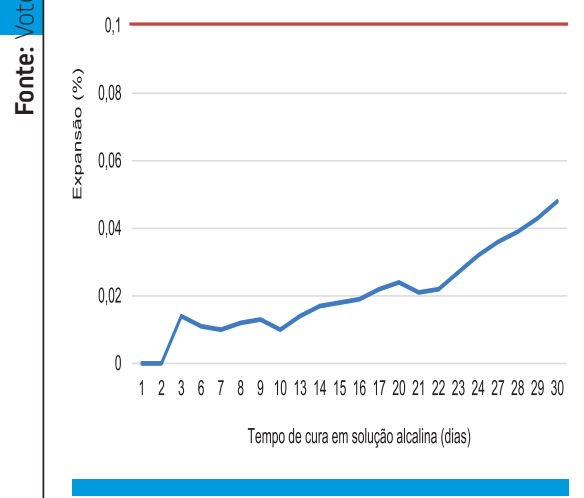

Figura 1

Variação dimensional de barras de argamassa feitas com agregado reativo e cimento CP IV, com teor álcalis de 1,33\%, $16 \%$ de cinzas volantese $10 \%$ filer calcário. Os resultados mostram que cimentos com elevada quantidade de álcalis são capazes de inibir reações álcali-agregado se tiverem teores adequados de adições

potencial para concreto massa, já que a elevação da temperatura e sua manutenção por períodos relativamente longos pode levar à fissuração. Como o calor de hidratação do cimento é bastante influenciado pelo seu teor de $\mathrm{C}_{3} \mathrm{~A}$, algumas especificações prescritivas para obras de barragens, entre outras, limitam o teor deste constituinte. No entanto, a redução do calor de hidratação pode ser conseguida com o uso de cimentos com adição.

\section{EVITANDO A CORROSÃO A PARTIR DA LIMITAÇÃO DO TEOR DE CLORETOS NO CONCRETO}

Algumas especificações limitam O teor de cloretos no cimento, com o objetivo de prevenir corrosão das armaduras

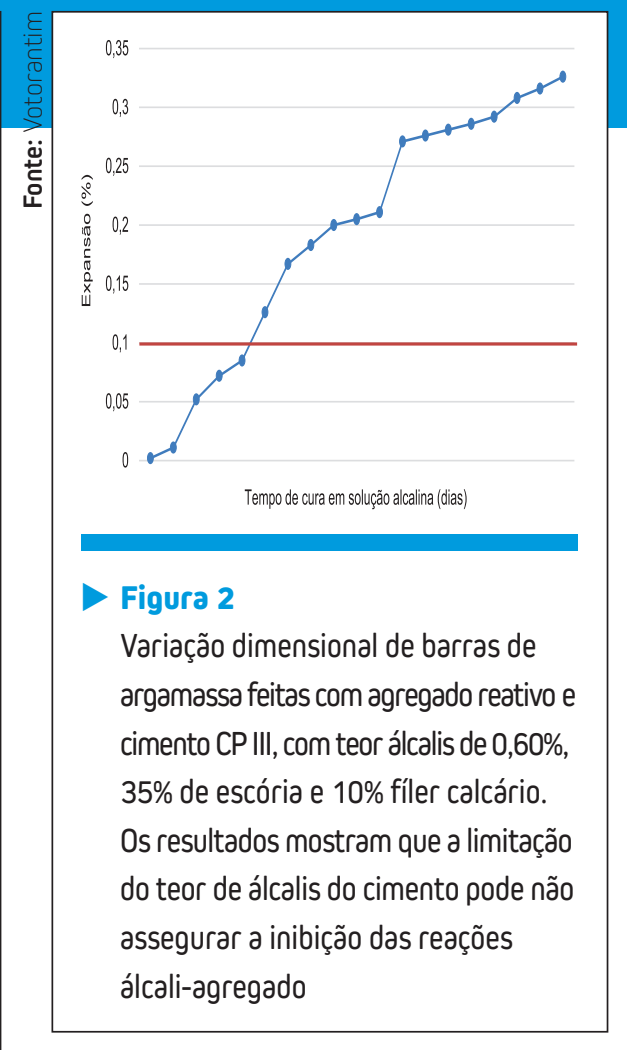

do concreto. Contudo, cloretos podem penetrar no concreto, se ele estiver em regiões litorâneas, por exemplo. Neste caso, as melhores medidas para prevenir corrosão por ação de cloretos são reduzir a relação água/cimento ou usar cimentos com teores elevados de escórias ou pozolanas. Em razão disso, a norma brasileira NBR 12655: 2015 estabelece valores limites máximos de a/c e mínimos de $f_{c k}$ para concretos sujeitos a fontes externas de cloretos, como águas salgadas, solos salinos, águas domar e seus respingos.

\section{CONSIDERAÇÕES FINAIS}

Conforme demonstram inúmeros estudos, especificações prescritivas para o cimento podem não ser efetivas para assegurar a durabilidade do concreto durante a vida útil de proje-

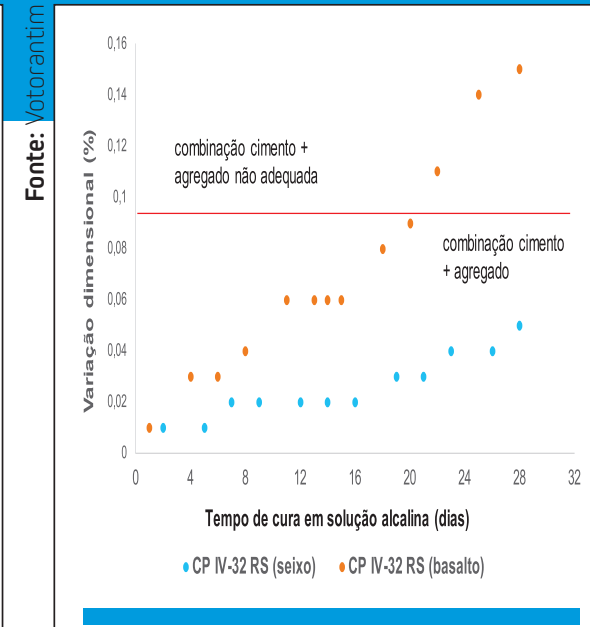

Figura 3

Variação dimensional de barras de argamassa feitas com CP IV e dois agregados reativos distintos, evidenciando que um mesmo cimentoécapaz ounão de inibir a reação álcali-agregado, dependendo da reatividade do agregado

to. Elas também limitam a otimização das propriedades do cimento e, em geral, têm impacto negativo em sua pegada ambiental.

Especificações baseadas no desempenho requerido, por outro lado, são mais claras quanto às características relevantes do produto, o que permite ao fabricante atender melhor às necessidades do cliente $e$, ao mesmo tempo, produzir um cimento mais sustentável.

De modo geral, o aumento da durabilidade e, consequentemente, da vida útil do concreto, é conseguido pela redução da relação água/cimento e pelo uso de cimentos com adições, já que elas contribuem para prevenir a maior parte dos processos que levam à deterioração do concreto.

\section{DREFERÊNCIAS BIBLIOGRÁFICAS}

[1] ASTM C 150 - 2017. Standard Specification For Portland Cement.

[2] EN 206 - 2016 Concrete. Specification, performance, production and conformity. CEN.

[3] Heisig, A., Urbonas, L., Beddoe, R.E., Heinz, D. Ingress of NaCl in concrete with alkali reactive aggregate: effect on silicon solubility. Materials \& Structures, 49, 4291-4303 (2016)

[4] NBR 12655: 2015. Concreto de cimento Portland - Preparo, controle, recebimento e aceitação - Procedimento.

[5] NBR 13583: 2014 Cimento Portland - Determinação da variação dimensional de barras de argamassa de cimento Portland expostas à solução de sulfato de sódio.

[6] NBR 16697: 2018 Cimento Portland - Requisitos.

[7] Monteiro, P. J. M., Kurtis, K. E. Time to failure for concrete exposed to severe sulfate attack. Cement and Concrete Research, 33, p. $987-993$ (2003).

[8] Stark, D. Performance of concrete in sulfate environments. PCA, Research \& Development Bulletin, RD 129, 2002. 